\title{
Ongoing efforts to reduce perioperative morbidity of radical cystectomy: towards widespread adoption of extended-duration thromboprophylaxis
}

\author{
Vignesh T. Packiam ${ }^{1}$, Joseph J. Pariser ${ }^{2}$ \\ ${ }^{1}$ Section of Urology, Department of Surgery, University of Chicago Pritzker School of Medicine, Chicago, IL, USA; ${ }^{2}$ Department of Urology, \\ University of Minnesota, Minneapolis, MN, USA \\ Correspondence to: Joseph J. Pariser, MD. Department of Urology, University of Minnesota, 420 Delaware St. SE, MMC 394, Minneapolis, MN \\ 55455, USA. Email: pariserj@gmail.com. \\ Provenance: This is a Guest Editorial commissioned by Section Editor Xiao Li (Department of Urologic Surgery, The Affiliated Cancer Hospital of \\ Jiangsu Province of Nanjing Medical University, Nanjing, China). \\ Comment on: Klaassen Z, Arora K, Goldberg H, et al. Extended Venous Thromboembolism Prophylaxis after Radical Cystectomy: A Call for \\ Adherence to Current Guidelines. J Urol 2017.
}

Submitted Jan 21, 2018. Accepted for publication Jan 29, 2018.

doi: $10.21037 /$ tau.2018.02.01

View this article at: http://dx.doi.org/10.21037/tau.2018.02.01

Radical cystectomy (RC) is the gold standard treatment for muscle invasive and select high-risk non-muscle invasive bladder cancers. The operation is well known to pose significant perioperative morbidity (1). Venous thromboembolic events (VTE) remain a major and increasingly acknowledged complication of RC. Until recently, there have been several obstacles to clear guidance on perioperative thrombophylaxis, including concerns regarding standardized reporting of VTE and questions about the risks of anticoagulation (2-4).

In a timely review by Tikkinen et al., procedurespecific VTE and bleeding risks after urologic surgery were outlined after a comprehensive literature review, with a clear demonstrable benefit of extended-duration thromboprophylaxis after RC (5). The question remains whether there has been adequate widespread adoption of post-discharge prophylaxis.

In a recent article published in fournal of Urology, Klaassen and associates assert the answer is no (6). They systematically expound on several key concepts. First, retrospective institutional series and large multiinstitutional databases reveal that symptomatic VTE occurs in $3-12 \%$ of patients undergoing RC (4-12). Importantly, more than half of these VTE occur after hospital discharge. Next, the article thoroughly reviews Level 1 evidence and a meta-analysis from the general surgery literature supporting the use of extended-duration thrombophylaxis, showing a greater than $50 \%$ reduction in VTE (7-9).

The specific benefit of extended-duration (postdischarge) VTE prophylaxis after RC has been evaluated at high-volume centers where it was initially adopted. We and others have previously described experiences instituting regimens consisting of post-discharge enoxaparin, which were associated with decreased VTE rates (10-12). Specifically, we reported a decrease in the rate of VTE from $12 \%$ to $5 \%$ with benefits predominantly in postdischarge events (6\% vs. 2\%) (10). Fortunately, bleeding rates did not measurably increase with post-discharge thromboprophylaxis in any of these series. The recent Tikkinen report further dispels fears of major bleeding requiring reoperation, estimating its incidence after RC is roughly $0.3 \%(5)$. While not yet clearly recommended from the American Urological Association (AUA), numerous other societies recommend approximately 4 weeks of "extended-duration" thrombophylaxis following RC.

While enoxaparin is generally safe and effective, novel low molecular weight heparin agents (Tinzaparin) and Factor Xa inhibitors (e.g., Apixaban) remain alternatives that warrant further investigation in this population, especially given the potential for oral administration and decreased risks in patients with renal insufficiency. Finally, the authors discuss data from an electronic AUA 
survey showing that $31 \%$ of respondents do not use any thrombophylaxis at all following RC, let alone an agent for an extended-duration (13).

In summary, this article acts as a timely and useful review of the rationale for aggressive VTE prophylaxis following RC. Hopefully, it will serve to educate and improve utilization for extended-duration regimens to decrease the longstanding high perioperative morbidity associated with RC.

\section{Acknowledgements}

None.

\section{Footnote}

Conflicts of Interest: The authors have no conflicts of interest to declare.

\section{References}

1. Shabsigh A, Korets R, Vora KC, et al. Defining early morbidity of radical cystectomy for patients with bladder cancer using a standardized reporting methodology. Eur Urol 2009;55:164-74.

2. Violette PD, Cartwright R, Briel M, et al. Guideline of guidelines: thromboprophylaxis for urological surgery. BJU Int 2016;118:351-8.

3. McAlpine K, Breau RH, Mallick R, et al. Current guidelines do not sufficiently discriminate venous thromboembolism risk in urology. Urol Oncol 2017;35:457.e1-457.e8.

4. Fantony JJ, Gopalakrishna A, Noord MV, et al. Reporting Bias Leading to Discordant Venous Thromboembolism Rates in the United States Versus Non-US Countries Following Radical Cystectomy: A Systematic Review and Meta-analysis. Eur Urol Focus 2016;2:189-96.

5. Tikkinen KAO, Craigie S, Agarwal A, et al. Procedure-

Cite this article as: Packiam VT, Pariser JJ. Ongoing efforts to reduce perioperative morbidity of radical cystectomy: towards widespread adoption of extended-duration thromboprophylaxis. Transl Androl Urol 2018;7(Suppl 1):S81-S82. doi: 10.21037/ tau.2018.02.01 specific Risks of Thrombosis and Bleeding in Urological Non-cancer Surgery: Systematic Review and Metaanalysis. Eur Urol 2018;73:236-41.

6. Klaassen Z, Arora K, Goldberg H, et al. Extended Venous Thromboembolism Prophylaxis after Radical Cystectomy: A Call for Adherence to Current Guidelines. J Urol 2017.

7. Bergqvist D, Agnelli G, Cohen AT, et al. Duration of prophylaxis against venous thromboembolism with enoxaparin after surgery for cancer. $\mathrm{N}$ Engl J Med 2002;346:975-80.

8. Rasmussen MS, Jorgensen LN, Wille-Jørgensen P, et al. Prolonged prophylaxis with dalteparin to prevent late thromboembolic complications in patients undergoing major abdominal surgery: a multicenter randomized openlabel study. J Thromb Haemost 2006;4:2384-90.

9. Fagarasanu A, Alotaibi GS, Hrimiuc R, et al. Role of Extended Thromboprophylaxis After Abdominal and Pelvic Surgery in Cancer Patients: A Systematic Review and Meta-Analysis. Ann Surg Oncol 2016;23:1422-30.

10. Pariser JJ, Pearce SM, Anderson BB, et al. Extended Duration Enoxaparin Decreases the Rate of Venous Thromboembolic Events after Radical Cystectomy Compared to Inpatient Only Subcutaneous Heparin. J Urol 2017;197:302-7.

11. Schomburg J, Krishna S, Soubra A, et al. Extended outpatient chemoprophylaxis reduces venous thromboembolism after radical cystectomy. Urol Oncol 2018;36:77.e9-77.e13.

12. Zaid HB, Yang DY, Tollefson MK, et al. Safety and Efficacy of Extended Duration of Thromboembolic Prophylaxis Following Radical Cystectomy: An Initial Institutional Experience. Urol Pract 2016;3:462-7.

13. Sterious S, Simhan J, Uzzo RG, et al. Familiarity and selfreported compliance with American Urological Association best practice recommendations for use of thromboembolic prophylaxis among American Urological Association members. J Urol 2013;190:992-8. 